\title{
GCU
}

Glasgow Caledonian

University

University for the Common Good

\section{Patient and public involvement for mental health researchers}

Parkinson, Ben; Lawrence, Maggie; Booth, Jo

Published in:

Mental Health Practice

DOI:

10.7748/mhp.2020.e1481

Publication date:

2021

Document Version

Author accepted manuscript

Link to publication in ResearchOnline

Citation for published version (Harvard):

Parkinson, B, Lawrence, M \& Booth, J 2021, 'Patient and public involvement for mental health researchers', Mental Health Practice, vol. 24, no. 6, e1481. https://doi.org/10.7748/mhp.2020.e1481

\section{General rights}

Copyright and moral rights for the publications made accessible in the public portal are retained by the authors and/or other copyright owners and it is a condition of accessing publications that users recognise and abide by the legal requirements associated with these rights.

Take down policy

If you believe that this document breaches copyright please view our takedown policy at https://edshare.gcu.ac.uk/id/eprint/5179 for details of how to contact us. 


\section{Patient and public involvement for mental health researchers.}

Conflict of interest: none declared

Key words: research; mental health; patient and public involvement.

\section{Abstract}

Background Patient and public involvement (PPI) involves working with patients and the public to make mental health research more relevant for those using services. The importance of PPI makes it necessary for mental health researchers to understand the practical and ethical issues involved in PPI.

Aim Increase mental health researchers understanding of the practical and ethical considerations associated with PPI.

Discussion PPI can make a positive contribution to mental health research. Mental health researchers need to consider how to make PPI meaningful and the best way of evaluating PPI. It is also important PPI is carried out ethically by considering issues of consent, professionalisation, authorship, payment, and tokenism.

Conclusion Mental health researchers produce more person-centred research with PPI. Mental health researchers need to anticipate potential practical and ethical challenges involved with PPI and develop strategies to deal with these effectively.

\section{Implications for practice}

- Patient and public involvement (PPI) can make mental health research better and more person-centred.

- Mental health researchers should involve people with lived experience of mental health difficulties at every stage of the research process.

- Being aware of the practical and ethical implications of PPI will help mental health researchers and PPI members produce meaningful, good quality, and clinically relevant mental health research. 


\section{Introduction}

Patient and public involvement (PPI) describes research that is carried out in partnership with patients and/or the public (INVOLVE, 2018b). PPI can help research become more patient-centred and relevant for the wider community (Hahn et al., 2017). Ennis and Wykes (2013) examined the use of PPI in mental health research and found it has been increasing in recent years, but is less likely to occur in research exploring personality disorders, developmental difficulties, and social interventions. Good examples of PPI within mental health research include a recent project to develop a shared decision making app for mental health, which involved young people and other stakeholders (Edridge et al., 2018). There are also excellent examples of people with lived experience of mental health being members of research teams and co-applicants on clinical trials (Lea et al., 2020). Likewise, mental health research has been successfully co-produced by people with lived experience (Faulkner et al., 2019). The range of studies involving PPI demonstrates the varied way PPI can be involved in mental health research and highlights the importance of all mental health researchers being familiar with PPI (Ennis and Wykes, 2013).

Strong arguments exist for why mental health researchers should engage with PPI. Brett et al. (2014) reviewed the potential advantages of PPI for researchers and discovered a number of benefits: pertinent research objectives, improved participant documentation, better recruitment, userorientated analysis, and enhanced dissemination. A second review explored the impact of PPI on the patients and public involved and found evidence of them having improved confidence and feeling valued (Brett, Staniszewska, Mockford, Herron-Marx, et al., 2014). As evidence for PPI grows it is becoming increasingly expected within mental health research (Ennis and Wykes, 2013) and it is often a requirement when applying for grant funding or publishing in academic journals (Price et al., 2018).

\section{Practical considerations}


The move towards increased PPI exists despite uncertainty in several areas: how best to implement PPI, how to make PPI meaningful, and how to evaluate the impact of PPI (Ocloo and Matthews, 2016). Implementation of PPI is helped by considering the different roles and functions of PPI within mental health research. A structured consensus group explored how PPI can be used and found it can contribute to research by highlighting priorities, shaping the research design, conducting the research, and sharing the findings of research (Gray-Burrows et al., 2018). However, Price et al. (2018) states sometimes researchers struggle to use PPI is in systematic reviews, although, there are many examples of PPI being used successfully in systematic reviews. A narrative review of PPI use within health and social care systematic reviews found several $(n=7)$ examples where PPI had been used successfully. The review found PPI can make a worthwhile contribution at every stage of the systematic review process, but a lack of funding and time pressure as potential barriers for PPI within systematic reviews (Boote, Baird and Sutton, 2011). However, there are also good examples of PPI being employed by doctorate students exploring self-harm in older adults (Troya et al., 2019). This evidence demonstrates the varied ways PPI can be incorporated into mental health research and highlights how PPI can add value to every stage of the research process (Bagley et al., 2016). Making PPI meaningful is an important consideration for mental health researchers and extends beyond simply implementing PPI in research. Ocloo and Matthews (2016) suggests current models of PPI are too narrow, which can inadvertently make PPI very exclusive. Exclusivity occurs when the PPI membership is not representative of the wider patient group (Ocloo and Matthews, 2016) or when the same group of people are involved repeatedly (Paul and Holt, 2017). Whilst meaningful PPI involves partnership working between researchers and PPI members. It should capture the voice of previously unheard people and make sure marginalised groups are being properly represented within research (Hoddinott et al., 2018). O'Hara and Lawton (2016) echo this thinking by highlighting the diversity that exists within patient groups and by stating researchers need to get better at encouraging different sectors of society to engage in PPI. Therefore, meaningful PPI should involve both true partnership working and diversity to reflect social complexity (Ocloo and Matthews, 2016). 
Evaluating PPI is another challenge for mental health researchers to consider. Edelman and Barron (2016) states PPI is often evaluated in terms of research success and quality, but it is important to not mistake PPI for an intervention with reproducible methods and quantifiable outcomes (Staley and Barron, 2019). This narrow focus overlooks the complexity of PPI and the potential benefits experienced by PPI members (Edelman and Barron, 2016). Rose (2014) states PPI is about more than just involving patient and/or the public in research and can be empowering and emancipatory for those involved. Holistic evaluation is needed to help capture the wide and varied impact PPI can have on research activity and the people involved. It is also helpful to think of PPI as meaningful dialogue between different parties with a focus on learning outcomes for both the researcher and PPI members (Staley and Barron, 2019). The potential for mental researchers to learn from PPI makes it an important developmental tool for researchers at every stage of their career and creates opportunity for them to develop and enhance transferable skills which are necessary for successful research (Staley and Barron, 2019).

\section{Possible challenges associated with PPI}

A Delphi study conducted in Belgium considered potential challenges associated with PPI. The study identified several potential risks including: lack of financial support, difficulty finding suitable PPI members, and PPI members who have vested interests in the outcome of the research (Cleemput et al., 2015). These issues are difficult to resolve, but careful planning can reduce the negative impact of these factors. For example, different providers are starting to offer financial support to fund PPI activity (Boote et al., 2015) and websites are available to help recruit people for PPI (People in Research, 2019). Hoddinott et al. (2018) suggest it is important for PPI members to consider whether they have any conflict of interest when engaged in PPI activity, because this could negatively affect the credibility of the research being undertaken. Researchers are routinely asked to self-disclose conflict of interests when publishing work and engaged in other scholarly activities (Bruton and Sacco, 2018). Similarly, PPI conflict of interest concerns could be resolved by asking PPI members to 
self-disclose any possible conflict of interests. The International Committee of Medical Journal Editors produce a standard self-disclosure template that is ideal for use by researchers and PPI members (Drazen, 2010).

It is also worth considering the possible risks for PPI members themselves. A systematic review explored the impact of PPI members and found some PPI members could experience negative consequences, including being over burdened by the work (Brett, Staniszewska, Mockford, HerronMarx, et al., 2014). Therefore, it is important for mental health researchers to be alert to the possibility of negative consequences for PPI members and should ensure that PPI members' contribution is manageable and not burdensome.

\section{Ethical considerations in PPI}

PPI is increasingly being used in mental health research, but this change in practice brings ethical considerations (Ennis and Wykes, 2013). Uncertainty about the ethical requirements for PPI has resulted in some researchers being asked to seek ethical approval and gain written consent from PPI members (Boote et al., 2015). However, using formal written consent processes and seeking ethical approval for PPI would create a power imbalance and jeopardise the collaborative nature of PPI (Smith et al., 2009). This position is supported by INVOLVE and the Health Research Authority who provided a joint statement stating ethical approval is not required for PPI (INVOLVE, 2016).

Formal research ethics committee approval might not be necessary, but it is still important to ensure PPI activity is carried out ethically. For example, agreement to participate in PPI should be given freely and in full knowledge of what will be involved (Hoddinott et al., 2018). A recent Delphi study was completed with researchers $(n=25)$ to establish what they saw as the ethical issues associated with PPI (Bélisle-Pipon, Rouleau and Birko, 2018). The study highlighted four main ethical concerns: professionalisation of PPI members, authorship, determining appropriate payment for PPI activity, and avoiding tokenism. 
Concern about the professionalization relates to whether PPI members are being overused and/or socialised to the research community (Bélisle-Pipon, Rouleau and Birko, 2018). Professionalization causes concern because it is thought PPI members might become over socialised to the research world and stop reflecting the patient group they are meant to represent (Ives, Damery and Redwod, 2013). Professionalization of PPI members might occur as a result of providing training about research methodology, for example, because it can familiarise then with the research community and the realities of the mental health research from the perspective of researchers and/or funders (Ives, Damery and Redwod, 2013). Conversely, Staley (2013) states training is important because it helps PPI members fulfil their role and is a perceived benefit of PPI. Likewise, PPI members have reported that a lack of adequate preparation can sometimes prevent them for fulfilling their PPI role (Brett, Staniszewska, Mockford, Herron-Marx, et al., 2014). Equally it is not necessary to have all PPI members trained in research and it can be desirable to have PPI members without any research experience or training for certain activities (Hoddinott et al., 2018).

Concern about authorship and appropriate acknowledgement of PPI in published work was another ethical concern highlighted by researchers (Bélisle-Pipon, Rouleau and Birko, 2018). This concern reflects the importance placed on academic authorship and the associated ethical implications of being an author (Horner and Minifie, 2011). The International Committee of Medical Journal Editors (2019) suggests authorship should be based on whether a person has made a substantial contribution to the research process, critically drafted the manuscript for intellectual content, approved the final version for publication, and whether they will be held accountable for the published work. The ICMJE's helps determine authorship for academic publications, but Shaw (2011) suggests the guidance is unsatisfactory because legitimate researchers might sometimes find it difficult to achieve all the criteria for authorship. This situation highlights the strict criteria used within the academic community to decide author status, but also highlights the challenges of authorship within the context of PPI (Bélisle-Pipon, Rouleau and Birko, 2018). Hewlett et al. (2006) resolves the issue of authorship by stressing how the rules of authorship apply equally to 
researchers and PPI members, which means anyone meeting the ICMJE criteria should be given author status. Alternatively, formal acknowledgement can be used when people have made a contribution, but do not meet full criteria for authorship (International Committee of Medical Journal Editors, 2019).

Payment of PPI activity is also a common ethical dilemma for mental health researchers and especially those working with a limited budget (Bélisle-Pipon, Rouleau and Birko, 2018). Hoddinott et al. (2018) recommends payment is agreed for PPI beforehand and takes into consideration the best method of payment and whether cash payment or vouchers would be preferred. INVOLVE (2016) have produced guidance on the payment and recommend payment at an appropriate level for the PPI activity completed. INVOLVE (2016) state appropriate payment should cover the PPI member's time, the efforts involved completing the activity, the expertise they bring to the role, and any expenses incurred during the PPI activity (e.g. accommodation and travel).

Another ethical challenge highlighted by researchers is how to avoid tokenistic PPI (Bélisle-Pipon, Rouleau and Birko, 2018). Tokenistic PPI is superficial and done as a 'tick box' exercise to please funding bodies or other external partners (Paul and Holt, 2017). Avoiding tokenism requires a longterm commitment and enduring relationships with PPI members (Hahn et al., 2017). Involving PPI in every stage of the research process, respecting each other's expertise, and working in partnership are essential ingredients for avoiding tokenistic PPI (Ocloo and Mathews, 2016).

PPI can create ethical dilemmas, but these can be overcome by following some basic principles. Ethical PPI is more likely when it is voluntary, non-burdensome, inclusive, collaborative, meaningful, and people are properly compensated for their efforts (Hoddinott et al., 2018). Using these basic principles helps maximise the potential of PPI within mental health research and will likely result in better quality and more relevant research.

\section{Conclusion}


PPI involves mental health researchers working in partnership with patient and/or public to produce better research (INVOLVE, 2018b). This partnership working is important at every stage of the research process and can make mental health research more person-centred and relevant for people experiencing mental health difficulties (Hahn et al., 2017). This paper highlights some of the practical and ethical considerations involved with PPI and offers guidance and basic principles for mental health researchers and PPI members.

\section{References}

Bagley, H. et al. (2016) ‘A patient and public involvement (PPI) toolkit for meaningful and flexible involvement in clinical trials - a work in progress', Research Involvement and Engagement, 2(1). doi: 10.1186/s40900-016-0029-8.

Bélisle-Pipon, J.-C., Rouleau, G. and Birko, S. (2018) 'Early-career researchers' views on ethical dimensions of patient engagement in research', BMC medical ethics, p. 21. doi: 10.1186/s12910-0180260-y.

Boote, J., Baird, W. and Sutton, A. (2011) 'Public involvement in the systematic review process in health and social care: A narrative review of case examples', Health policy, 102(2), pp. 105-116. doi: 10.1016/j.healthpol.2011.05.002.

Boote, J. D. et al. (2015) 'Supporting public involvement in research design and grant development: a case study of a public involvement award scheme managed by a National Institute for Health Research (NIHR) Research Design Service (RDS)', Health expectations., pp. 1481-1493. doi: 10.1111/hex.12130.

Brett, J., Staniszewska, S., Mockford, C., Herron-Marx, S., et al. (2014) 'A Systematic Review of the Impact of Patient and Public Involvement on Service Users, Researchers and Communities', Patient. Springer International Publishing, pp. 387-395. doi: 10.1007/s40271-014-0065-0.

Brett, J., Staniszewska, S., Mockford, C., Herron-Marx, S., et al. (2014) 'Mapping the impact of 
patient and public involvement on health and social care research: a systematic review', Health Expectations, pp. 637-650. doi: 10.1111/j.1369-7625.2012.00795.x.

Bruton, S. V and Sacco, D. F. (2018) 'What's it to me? Self-interest and evaluations of financial conflicts of interest', Research Ethics. SAGE PublicationsSage UK: London, England, 14(4), pp. 1-17. doi: $10.1177 / 1747016117739940$.

Cleemput, I. et al. (2015) 'Acceptability and Perceived Benefits and Risks of Public and Patient Involvement in Health Care Policy: A Delphi Survey in Belgian Stakeholders', Value in health., pp. 477-483. doi: 10.1016/j.jval.2014.12.015.

Drazen, J. M. (2010) 'Toward More Uniform Conflict Disclosures: The Updated ICMJE Conflict of Interest Reporting Form', Annals of internal medicine., p. 268. doi: 10.7326/0003-4819-153-4$201008170-00261$.

Edelman, N. and Barron, D. (2016) 'Evaluation of public involvement in research: time for a major rethink?', Journal of health services research \& policy, 21(3), pp. 209-211. doi: $10.1177 / 1355819615612510$.

Edridge, C. L. et al. (2018) 'Power Up: Patient and public involvement in developing a shared decision-making app for mental health', JHD, 3(1), p. 63. doi: 10.21853/JHD.2018.40.

Ennis, L. and Wykes, T. (2013) 'Impact of patient involvement in mental health research: longitudianl study', British Journal fo Psychiatry, 203, pp. 381-386. doi: 10.1192/bjp.bp.112.119818.

Faulkner, A. et al. (2019) “'Dignity and respect”: An example of service user leadership and coproduction in mental health research', Health Expectations, p. hex.12963. doi: 10.1111/hex.12963. Gray-Burrows, K. et al. (2018) 'Role of patient and public involvement in implementation research: a consensus study', BMJ Quality \& Safety, p. 858. doi: 10.1136/bmjqs-2017-006954.

Hahn, D. L. et al. (2017) 'Tokenism in patient engagement', Family practice, 34(3), pp. 290-295. doi: 
10.1093/fampra/cmw097.

Hewlett, S. et al. (2006) 'Patients and professionals as research partners: Challenges, practicalities, and benefits', Arthritis Care \& Research, 55(4), pp. 676-680. doi: 10.1002/art.22091.

Hoddinott, P. et al. (2018) 'How to incorporate patient and public perspectives into the design and conduct of research', F1000Research. doi: 10.12688/f1000research.15162.1.

Horner, J. and Minifie, F. (2011) 'Research Ethics III: Publication Practices and Authorship, Conflicts of Interest, and Research Misconduct', Journal of Speech, Language and Hearing Research (Online), 54(1), p. S362A. doi: 10.1044/1092-4388(2010/09-0263).

International Committee of Medical Journal Editors (2019) ICMJE / Recommendations / Defining the Role of Authors and Contributors. Available at:

http://www.icmje.org/recommendations/browse/roles-and-responsibilities/defining-the-role-ofauthors-and-contributors.html (Accessed: 15 March 2019).

INVOLVE (2016) Public involvement in research and research ethics committee review Purpose. Available at: www.involve.nihr.ac.uk (Accessed: 14 March 2019).

INVOLVE (2018a) National Standards for Public Involvement. Available at: http://www.invo.org.uk/wp-content/uploads/2018/06/Public_Involvement_Standards_v1.pdf (Accessed: 14 March 2019).

INVOLVE (2018b) ‘National Standards for Public Involvement'. Available at: https://www.invo.org.uk/wp-content/uploads/2018/06/Public_Involvement_Standards_v1.pdf. Ives, J., Damery, S. and Redwod, S. (2013) ‘PPI, paradoxes and Plato: who's sailing the ship?', Journal of medical ethics, 39(3), pp. 181-185. doi: 10.1136/medethics-2011-100150.

Lea, L. et al. (2020) 'Reflections on my role as a mental health service user co-applicant in a randomized control trial', Research for All, 4(1), pp. 33-46. doi: 10.18546/RFA.04.1.04. 
O'Hara, J. and Lawton, R. (2016) 'At a crossroads? Key challenges and future opportunities for patient involvement in patient safety', BMJ Qual Saf, 25. doi: 10.1136/bmjqs-2016-005476.

Ocloo, J. and Mathews, R. (2016) 'From tokenism to empowerment: progressing patient and public involvement in healthcare improvement', BMJ Qual Saf. doi: 10.1136/bmjqs-2015-004839.

Paul, C. and Holt, J. (2017) 'Involving the public in mental health and learning disability research: Can we, should we, do we?', Journal of psychiatric and mental health nursing , 24(8), pp. 570-579. doi: 10.1111/jpm.12404.

People in Research (2019). Available at: https://www.peopleinresearch.org/ (Accessed: 15 March 2019).

Price, A. et al. (2018) 'Frequency of reporting on patient and public involvement (PPI) in research studies published in a general medical journal: a descriptive study', BMJ Open. British Medical Journal Publishing Group, 8(3), p. e020452. doi: 10.1136/BMJOPEN-2017-020452.

Rose, D. (2014) 'Patient and public involvement in health research: Ethical imperative and/or radical challenge?', Journal of Health Psychology. SAGE PublicationsSage UK: London, England, 19(1), pp. 149-158. doi: 10.1177/1359105313500249.

Shaw, D. (2011) 'The ICMJE's definition of authorship is illogical and unethical.', BMJ (Clinical research ed.). British Medical Journal Publishing Group, 343, p. d7192. doi: 10.1136/bmj.d7192.

Smith, E. et al. (2009) 'Getting ready for user involvement in a systematic review', Health Expectations, 12(2), pp. 197-208. doi: 10.1111/j.1369-7625.2009.00535.x.

Staley, K. (2013) 'There is no paradox with PPI in research', Journal of Medical Ethics, 39(3), pp. 186187. doi: $10.1136 /$ medethics-2012-100512.

Staley, K. and Barron, D. (2019) 'Learning as an outcome of involvement in research: what are the implications for practice, reporting and evaluation?', Research Involvement and Engagement. 
BioMed Central, 5(1), p. 14. doi: 10.1186/s40900-019-0147-1.

Troya, M. I. et al. (2019) 'Patient and Public Involvement and Engagement in a doctoral research project exploring self-harm in older adults', Health Expectations. Wiley. doi: 10.1111/hex.12917. 
